\title{
Pathogenetic Mechanisms of Hepatitis C Virus-Induced B-Cell Lymphomagenesis
}

\author{
Fabio Forghieri, Mario Luppi, Patrizia Barozzi, Rossana Maffei, Leonardo Potenza, \\ Franco Narni, and Roberto Marasca
} Section of Hematology, Department of Oncology, Hematology, and Respiratory Diseases, University of Modena and Reggio Emilia,
41100 Modena, Italy

Correspondence should be addressed to Roberto Marasca, roberto.marasca@unimore.it

Received 26 April 2012; Accepted 1 June 2012

Academic Editor: Jürg Schifferli

Copyright ( $\odot 2012$ Fabio Forghieri et al. This is an open access article distributed under the Creative Commons Attribution License, which permits unrestricted use, distribution, and reproduction in any medium, provided the original work is properly cited.

Hepatitis C virus (HCV) infection is probably the most common chronic viral infection and affects an estimated 180 million people worldwide, accounting for $3 \%$ of the global population. Although the liver is considered to be the primary target, extrahepatic manifestations are well recognized among patients with chronic HCV infection. Epidemiological studies have clearly demonstrated a correlation between chronic HCV infection and occurrence of B-cell non-Hodgkin's lymphomas (B-NHL). The clinical evidence that antiviral therapy has a significant role in the treatment at least of some HCV-associated lymphoproliferative disorders, especially indolent B-NHL, further supports the existence of an etiopathogenetic link. However, the mechanisms exploited by HCV to induce B-cell lymphoproliferation have so far not completely clarified. It is conceivable that different biological mechanisms, namely, chronic antigen stimulation, high-affinity interaction between HCV-E2 protein and its cellular receptors, direct HCV infection of B-cells, and "hit and run" transforming events, may be combined themselves and cooperate in a multifactorial model of HCV-associated lymphomagenesis.

\section{Introduction}

Hepatitis C virus (HCV) is an enveloped positive, singlestranded RNA virus, belonging to the Flaviviridae family [1]. During its replicative cycle it goes through a negative-stranded RNA, but not DNA, intermediate, so that integration of HCV nucleic acid sequences into the host genome seems unlikely. The HCV genome encodes a single polyprotein precursor of approximately 3000 amino acids, which is proteolytically processed by viral and cellular proteases to produce structural (nucleocapsid, E1, and E2) and nonstructural (NS) proteins (NS2, NS3, NS4A, NS4B, NS5A, and NS5B). The HCV envelope proteins consist of two heavily glycosylated proteins, E1 and E2, which act as the ligands for cellular receptors $[1,2]$.

Human CD81 is the first identified necessary receptor for HCV cell entry, which can directly bind with HCV E2 protein $[3,4]$. CD81 is a widely distributed cell-surface tetraspanin that participates in different molecular complexes on various cell types, including hepatocytes, B-lymphocytes, T-lymphocytes, and natural killer cells. It has been proposed that HCV exploits CD81 not only to invade hepatocytes but also to modulate the host immune responses [5].

Infection with $\mathrm{HCV}$ affects an estimated 180 million people, accounting for $3 \%$ of the global population [6, 7]. HCV is a well-recognized etiologic agent of chronic hepatitis. Although the natural history of HCV infection is highly variable, an estimated $15 \%$ to $30 \%$ of patients in whom chronic infection develops have progression to cirrhosis over the ensuing three decades, and these latter patients warrant surveillance for complications, including hepatocellular carcinoma (HCC), which develops in 1\%-3\% of such patients per year $[6,7]$. Indeed, the risk of HCC in the HCV-infected population is $23-35$ times higher than in noninfected healthy individuals $[8,9]$. 
Although the liver is considered to be the primary target of HCV infection, extrahepatic manifestations, such as mixed cryoglobulinemia (MC), which is a systemic immune complex-mediated disorder characterized by B-cell proliferation that may evolve into overt B-cell non-Hodgkin's lymphoma (B-NHL) in about $10 \%-20 \%$ of patients several years after diagnosis, are often recognized among patients with chronic HCV infection [10-12]. Moreover, epidemiological evidences strongly suggest a close link between chronic HCV infection and de novo B-NHL, not complicating the course of MC [13-16]. The possible pathogenetic mechanisms of $\mathrm{HCV}$-induced B-cell lymphomagenesis are reviewed.

\section{Epidemiologic Association of HCV and B-NHL}

Evans and Mueller proposed that either epidemiologic or virologic guidelines need to be fulfilled to support an etiologic role for a virus in a given human cancer [17]. Suggested epidemiologic guidelines included the following: (a) the geographic distribution of viral infection should coincide with that of the tumor; (b) the presence of viral markers should be higher in case subjects than in matched control subjects; (c) viral markers should precede the tumor, with a higher incidence of tumors in persons with the marker than in those without; (d) prevention of viral infection should decrease tumor incidence [17]. Suggested virologic guidelines included the following: (a) the virus should be able to transform human cells in vitro; (b) the viral genome should be demonstrated in tumor cells and not in normal cells; (c) the virus should be able to induce the tumor in an experimental animal [17].

As far as the association between HCV infection and occurrence of B-NHL is concerned, most of the epidemiologic guidelines for causality from Evans and Mueller are met. $\mathrm{HCV}$ is associated with certain B-NHL types, especially in geographic areas with HCV endemicity, like Italy, Japan, and Egypt, where prevalence rates range from 20\% to $40 \%$ $[14,15,18-21]$, whereas in nonendemic areas, as Northern Europe, North America and United Kingdom, the prevalence of HCV infection in B-NHL is far less than 5\% [22-24]. The possibility is raised that in these latter geographic areas where HCV prevalence among subjects not affected with BNHL is low, the spread of the virus may be recent, thus not allowing the full consequences on B-NHL development to be observed. Moreover, studies from areas with low HCV prevalence may not have included sufficient numbers of patients to detect a significant association between $\mathrm{HCV}$ and B-NHL [16]. Taken together, the epidemiologic analyses demonstrated that the prevalence of $\mathrm{HCV}$ infection in patients with B-NHL is approximately $15 \%$ [25]. The prevalence of anti-HCV antibodies and/or HCV RNA sequences is significantly higher in patients with B-NHL than in patients with other lymphoid malignancies or in age matched healthy subjects. Furthermore, HCV infection often precedes by years the occurrence of lymphomas [26]. In a recent metaanalysis focusing on 15 studies, the pooled relative risk (RR) of all B-NHL among HCV-positive persons was found to be
2.5 (95\% confidence interval (CI), 2.1-3.1) in case-control studies and $2.0(95 \% \mathrm{CI}, 1.8-2.2)$ in cohort studies [27]. Another meta-analysis reviewed data from 23 studies $(4,049$ NHL patients and 1,813,480 controls) and found a stronger association (odds ratio 5.70) [28]. It should be noted that RR, although moderate (2-3 on average) in comparison to $\mathrm{HCV}$ and HCC association, were similarly increased for all major B-NHL subtypes and primary sites of presentation [16, 29]. Only slightly higher RR for extranodal compared with nodal B-NHL were reported for HCV-positive patients, but this difference was largely due to the early studies. Moreover, extensive studies did not demonstrate clear differences on the association between HCV and major histologic BNHL subtypes, either indolent, namely, follicular, marginal zone (MZL), lymphoplasmacytic, and chronic lymphocytic leukemia/small lymphocytic lymphoma, or aggressive diffuse large B-cell (DLBCL) and Burkitt lymphoma [16, 29, 30]. In fact, earliest studies suggesting a stronger association of HCV with certain subtypes, such as lymphoplasmacytic/Waldenstrom lymphomas, were performed mainly in HCV-infected subjects with MC, a subset of patients in which these lymphoma subtypes have been reported to be highly prevalent $[16,29]$. Conversely, one of the largest casecontrol studies to date found a higher OR (3.5 versus 2.3) for aggressive versus indolent lymphomas, respectively, and suggested that previous data may have also been influenced by the relatively poorer prognosis associated with aggressive lymphomas [14]. Patients with HCV-related DLBCL may have more aggressive clinical features at presentation in comparison to HCV-negative patients [31, 32].

The possible association between specific viral genotypes and malignant lymphoproliferative disorders remains a controversial issue. There are at least six major HCV genotypes whose prevalence varies geographically. Genotype 1 accounts for the majority of infections in North America, South America, and Europe [7]. Various clinical studies failed to demonstrate a link between specific viral genotypes and B-NHL, but it should also be noted that this issue was not specifically addressed in several other series. Luppi et al. documented an unexpectedly lower prevalence of HCV genotype $1 \mathrm{~b} / \mathrm{II}$ in patients with B-NHL. Conversely, the prevalence of genotypes $2 \mathrm{a} / \mathrm{III}$ and $2 \mathrm{~b} / \mathrm{IV}$ was higher in patients with B-NHL than in either hemodialysis or chronic liver disease patients, thus suggesting that different HCV variants may show greater lymphotropism [33]. Recent epidemiologic evidence from a multicenter retrospective study also suggested that genotype 2 may be more prevalent and carcinogenic in lymphoma patients [34]. In details, HCV-positive patients were classified as cancer patients (129 patients, including 53 hematologic malignancies and 76 solid tumors), immunocompetent (333 subjects) and HCVHIV coinfected (102 patients). Genotype 1 predominated (84\%) in immunocompetent as compared to patients with HCC $(74 \%, P=.08)$ or lymphoma $(59 \%, P=.001)$. By contrast, genotype 2 was more prevalent in patients with lymphoma (24\%), compared to immunocompetent $(8 \%, P=.003)$, yielding a 3 -fold increase in cancer risk among $\mathrm{HCV}$-infected patients than other genotypes [34]. Interestingly, Pellicelli et al. [19] observed that DLBCL 
patients had a higher prevalence of genotype 1 and a shorter duration of HCV infection, as compared to patients with indolent, low-grade B-NHL, who showed a higher prevalence of genotype 2 and longer duration of HCV infection. Because $\mathrm{HCV}$ genotype 2 is associated with a longer duration of viral infection, it has been speculated that over time it may induce a persistent chronic immunostimulation of Bcells. On the contrary, direct lymphocyte transformation could be hypothesized for HCV genotype 1 in aggressive lymphomas, on the basis of the shorter duration of viral exposure [19]. Future perspective studies enrolling a large number of patients are warranted to further investigate the different distribution and carcinogenic potential of different $\mathrm{HCV}$ genotypes.

The regression of HCV-related B-NHL following antiviral therapy probably represents the strongest argument in favor of an etiologic link between HCV infection and certain human lymphomas $[16,26]$. Several clinical trials showed that antiviral therapy, mostly based on peg-interferon and ribavirin, resulted in either complete or partial remissions of lymphoma in HCV-positive but not HCV-negative BNHL patients [29, 35-37]. A systematic review has shown that complete responses were achieved in $75 \%$ of the HCV-positive cases [38]. Lymphoma regression was usually positively correlated with viral load reduction [29]. These trials have been conducted in asymptomatic indolent lymphomas during a phase in which no other therapeutic intervention was administered. For aggressive lymphoma or symptomatic indolent lymphoma, $\mathrm{HCV}$ eradication alone is not an option. These patients require systemic therapy with rituximab and chemotherapy-based regimens as first treatment. Nevertheless, antiviral therapy to eradicate HCV may be an option after successful lymphoma therapy. Whether HCV eradication after-chemoimmunotherapy may impact future survival outcome remains uncertain [29]. Regarding this topic, La Mura et al. retrospectively analyzed 343 patients affected with NHL [39]. Twenty-five of the 69 HCV-positive subjects received antiviral therapy (interferon and ribavirin) following antineoplastic treatment, in order to eradicate HCV infection. Overall survival (OS) was slightly better in HCV-infected NHL patients treated with antiviral therapy compared with untreated, even if without statistically significance. Conversely, disease-free survival (DFS) was significantly improved in treated versus untreated patients. A sustained virologic response was obtained in $8 / 25$ (32\%) HCV-positive NHL patients who underwent antiviral treatment. None of the patients who eradicated $\mathrm{HCV}$ infection had a lymphoma relapse at followup, whereas $5 / 17$ of those who did not respond to antiviral therapy experienced relapses. At multivariate analysis, the independent factors related to a better DFS in this series were antiviral therapy and indolent histology at the onset of lymphoma [39]. Antiviral treatment may be a strategy to reinforce the results of successful chemoimmunotherapy regimens, but future prospective studies are needed to further investigate this clinical issue. Of interest, a recent study has shown that $\mathrm{HCV}$-infected patients who had received interferon therapy and had experienced a sustained virologic response had a hazard ratio of lymphomagenesis that was significantly lower than patients who had not received antiviral treatment [40]. These data suggest that antiviral treatment may also be efficacious in preventing lymphomagenesis in HCV-infected patients. Moreover, it should be of interest to investigate the impact of newer directly acting antiviral agents, such as protease inhibitors telaprevir and boceprevir [11, 41-43], on the future prevalence and clinical outcome of B-NHL in patients with chronic HCV infection. While reactivation risk of hepatitis B virus (HBV) after chemoimmunotherapy is well recognized and prophylactic antiviral therapy to suppress HBV-DNA is widely recommended, the issue of HCV reactivation in lymphoma patients undergoing antineoplastic treatments is lesser understood $[29,44]$. However, a significant proportion of patients with $\mathrm{HCV}$-positive NHL, when treated with conventional chemoimmunotherapy, may develop liver toxicity due to either direct cytotoxicity or increased drug toxicity from suboptimal drug metabolism $[29,45]$. The addition of rituximab to chemotherapy does not seem to impact significantly on liver toxicity [45]. HCVRNA levels appear to increase during chemoimmunotherapy as a result of viral reactivation, but HCV-RNA levels subsequently decrease at 6 months posttreatment, often without major clinical consequences to most patients [44]. Nevertheless, it should also be noted that massive liver necrosis may occur in HCV-positive lymphoma patients on withdrawal of chemotherapy or reduction of corticosteroids, suggesting an immune-mediated mechanism of hepatic damage $[44,46]$. Without initial liver dysfunction, HCVpositive patients with NHL could experience a similar outcome compared with their HCV-negative counterparts, when treated with conventional chemoimmunotherapy [44, 47]. A protective role of antiviral prophylaxis to suppress HCV replication during antineoplastic treatments has not yet been defined $[29,44]$. Prospective studies and longer followups are necessary to ascertain whether HCV-positive B-NHL patients have inferior outcome or whether there would be long term consequences of chemoimmunotherapy on the progression of liver disease [47]. Patients with HCV infection and lymphoma are recommended to be carefully monitored for hepatotoxicity and HCV-RNA levels. Furthermore, hematologists and hepatologists should work closely together in order to optimize the management of HCV infection throughout lymphoma treatment and improve clinical outcome [29].

\section{Mechanisms of HCV-Induced Lymphoproliferation}

The biological rational for investigating a causal association between HCV infection and the occurrence of B-NHL is based on epidemiological and clinical observations. Nevertheless, limited information are so far available about the biological mechanisms of HCV-induced lymphoproliferation. Evidences from experimental studies suggest that several different mechanisms may be involved in HCV-mediated Bcell transformation $[16,29,48]$.

Similarly to the association of Helicobacter pylori infection and gastric MALT lymphoma, the concept of chronic 


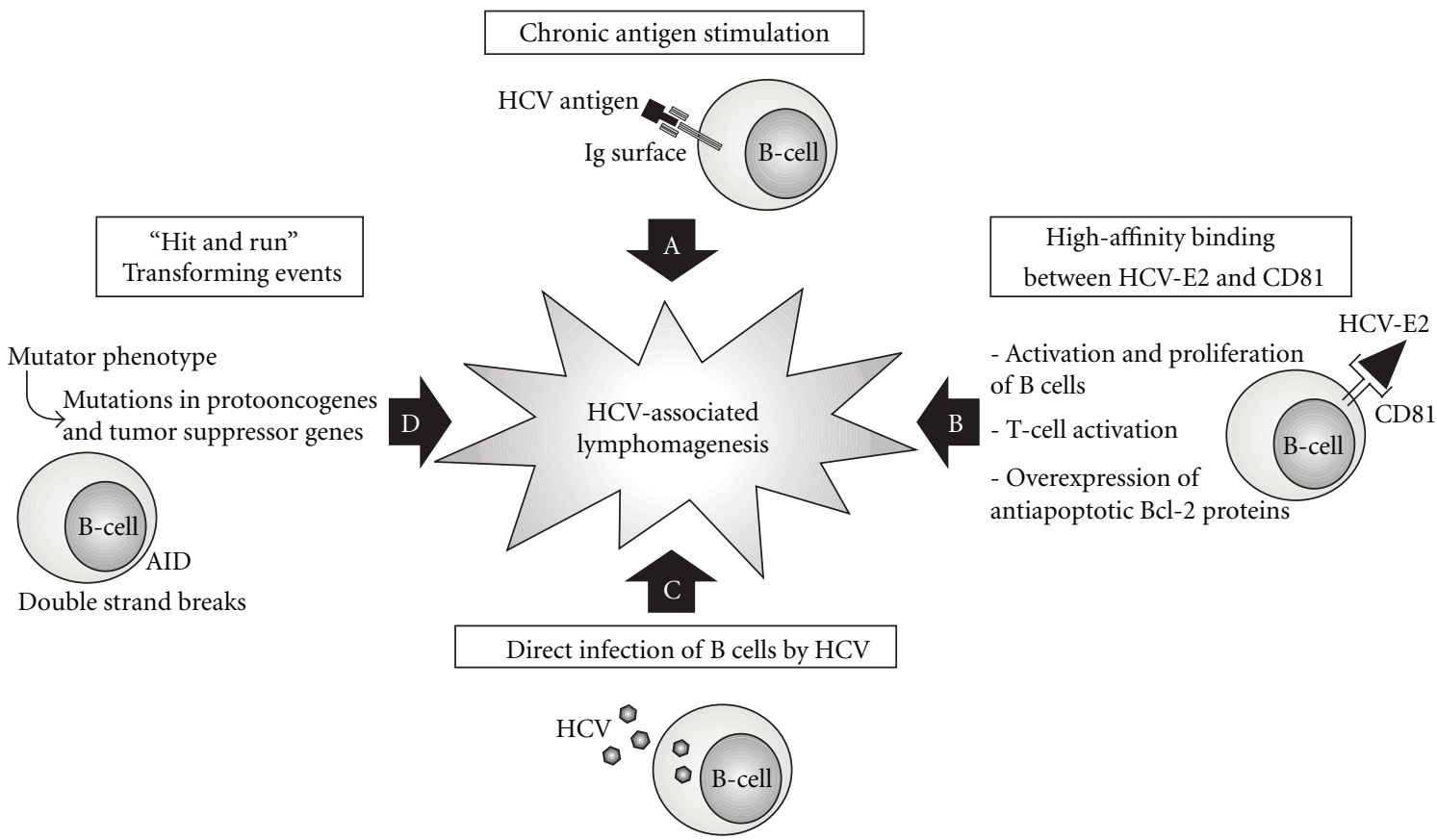

Figure 1: (A-D) The different oncogenetic mechanisms are not mutually exclusive, but they may be integrated and cooperate in a multifactorial pathogenetic model of $\mathrm{HCV}$-associated B-cell lymphoproliferation.

antigen stimulation leading to a monoclonal malignant proliferation may also be applied to HCV (Figure 1(A)) $[49,50]$. Interestingly, HCV-associated B-NHL generally originate from germinal center (GC) or post-GC B-cells, suggesting that lymphomagenesis occurs when B-cells experience somatic hypermutation and proliferate in response to an antigen $[51,52]$. Further evidence comes from the antibody response and immunoglobulin variable ( $\mathrm{Ig} \mathrm{VH})$ gene usage in patients with chronic HCV infection and $\mathrm{HCV}$-associated B-NHL. In three out of five HCV-positive nodal MZLs, Marasca et al. revealed the usage of the VH169 gene with similar CDR3, indicating a highly biased and nonrandom use of the $\mathrm{VH}$ segments in this subtype of tumors [53]. These data indicated the role of a common antigenic epitope involved in the selection and in the expansion of the B-cell clone at the origin of neoplastic cells. The VH1-69 immunoglobulin segment is expressed in the restricted repertoire of fetal liver B lymphocytes and is thought to be involved in natural immunity. A productive VH1-69 rearrangement is present in 1.6\% of normal B lymphocytes in adults. VH1-69 is rearranged in $10 \%$ to $20 \%$ of B-cell chronic lymphocytic leukemia and a VH1-69 monoclonal rearrangement is also present in the majority of patients with type II MC, a typical HCV-related disorder [53]. Further experimental sequencing of clonal Ig variable regions from both $\mathrm{MC}$ and $\mathrm{HCV}$-associated B-NHL patients documented restricted $\mathrm{IgV}$ gene repertoire, with expression of $\mathrm{VH}$ and $\mathrm{VL}$ genes (VH1-69 and $\mathrm{V} \kappa 3-\mathrm{A} 27$ ), suggesting exposure and response to a common antigen [54-56]. Of note, HCV-E2 protein is the primary target of antibody responses against HCV [57]. Quinn et al. obtained the cloning of the B-cell receptor from one HCV-positive DLBCL and its expression as a soluble immunoglobulin [58]. The immunoglobulin rescued was shown to bind the HCV-E2 glycoprotein in a manner identical to a bona fide human anti-E2 antibody, suggesting that some HCV-associated BNHL may originate from B-cells that were initially activated by HCV-E2 protein [58]. Similarly, in a reported case of an HCV-associated plasma cell leukemia, immunoblotting showed that the monoclonal IgG-kappa detected in the serum was directed against a viral protein, namely, the HCV core protein [59]. These and other studies suggest an indirect, antigen-driven lymphomagenetic role of $\mathrm{HCV}$, with HCV-E2 protein recognized as one of the most important antigens involved in chronic B-lymphocyte stimulation [16, $26,29]$.

A second mechanism, potentially involved in HCVassociated lymphomagenesis, derives from the high-affinity binding between HCV-E2 and one of its receptors, the tetraspanin CD81, expressed on B-cells (Figure 1(B)) [16]. CD81 is known to form B-cell costimulatory complex with CD19, CD21, and interferon-inducible Leu-13 (CD225) proteins. This complex reduces the threshold for B-cell activation via the B-cell receptor by bridging antigen specific recognition and $\mathrm{CD} 21$-mediated complement recognition $[60,61]$. It was reported that engagement of CD81 on human B-cells by a combination of HCV E2 protein and anti-CD81 $\mathrm{mAb}$ leads to the proliferation of naive B-cells, and E2CD81 interaction induces protein tyrosine phosphorylation and hypermutation of the immunoglobulin genes in Bcell lines [62]. In addition to direct effects on B-cells, engagement of CD81 on T-cells lowered the threshold for interleukin-2 production, resulting in strongly increased Tcell proliferation. This could lead to T-cell activation in 
response to suboptimal stimuli and bystander activation of B-cells [63]. Taken together, these results suggest that CD81 engagement on B- and T-cells may lead to direct or indirect activation [16]. Chronic B-cell proliferation, in response to antigenic stimulation or polyclonal activation, may predispose to genetic lesions such as translocation and/or overexpression of the antiapoptotic protein $\mathrm{Bcl}-2$ [64]. In a recent study, human Burkitt's lymphoma cell line (Raji cells) and primary human B lymphocytes (PHB) were treated with HCV-E2 protein and HCV particles produced by cell culture (HCVcc) [65]. The results showed that both E2 and HCVcc triggered phosphorylation of $\operatorname{IkB} \alpha$, with subsequent increased expression of NF-kB and NF-kB target genes, such as antiapoptotic Bcl-2 family proteins (Bcl-2 and $\mathrm{Bcl}-\mathrm{xL}$ ). Either Raji cells or PHB cells were protected from FAS-mediated death. In addition, both E2 protein and $\mathrm{HCV} c \mathrm{increased}$ the expression of costimulatory molecules CD80, CD86, and CD81 itself, and decreased the expression of complement receptor $\mathrm{CD} 21$. The effects were dependent on E2-CD81 interaction on the cell surface, since CD81silenced Raji cells did not respond to both treatments. Moreover, an E2 mutant that loses the CD81 binding activity could not trigger the responses of both Raji cells and PHB cells. Of note, the effects were not associated with HCV replication in cells [65]. Hence, E2-CD81 engagement plays a role in activating B-cells, protecting B-cells from activationinduced cell death, and regulating immunological function. These latter mechanisms may contribute to the pathogenesis of HCV-associated B-cell lymphoproliferative disorders [65]. Moreover, the interaction between HCV-E2 and CD81 on Bcells has been shown to stimulate the enhanced expression of activation-induced cytidine deaminase (AID) and to induce double-strand DNA breaks in the IgVH gene locus, thereby contributing to a mutator phenotype that increases the risk of B-cell malignant transformation [66].

Another oncogenetic mechanism that has been proposed is the direct infection of B-cells by HCV (Figure $1(\mathrm{C})$ ) $[16,29,67]$. In the early 1990s, the presence of HCVRNA was demonstrated by PCR not only in serum/plasma and liver tissues but also in peripheral blood mononuclear cells (PBMCs), especially in B-cells, of patients infected with HCV [68-71]. Nevertheless, although HCV has been detected in lymphocytes from HCV infected patients and patients with MC, only in a minority of cases RNA-negative strands, the HCV replicative intermediates suggestive of viral replication, were also detected in the cells [72-74]. Detection of negative-strands HCV-RNA in PBMCs by polymerase chain reaction, may also be due to either contamination or passive absorption of circulating $\mathrm{HCV}$, thus potentially leading to false positive results $[75,76]$. Marukian et al. showed that culture-grown HCV replicated in hepatoma cells, but no HCV replication was detected in B- or T-cells, monocytes, macrophages, or dendritic cells from healthy donors [77]. Furthermore, Stamataki et al. have provided experimental evidence that HCV might infect B-cells, but B-cells were not able to support active viral replication [78]. Overall, these results should indicate that PBMC may not be permissive to $\mathrm{HCV}$ replication [16].
However, it has been reported that HCV may infect and replicate only in a relatively rare subset of B-cells, such as CD5+ B-cells. These cells have been shown to express high levels of CD81 and to expand in HCV-infected liver [79]. Alternatively, B-cells may need another event, such as coinfection with another virus, namely, Epstein-Barr virus (EBV), to become permissive for HCV infection and replication $[16,80]$. Neither HCV-RNA nor viral proteins have generally been detected in lymphomatous cells in vivo, with a few exceptions, for example a primary DLBCL of the liver, found to harbor viral nucleic acids by in situ hybridization and a mantle cell lymphoma case, from which a lymphoma cell line could be established in vitro $[26,81$, 82]. Moreover, Sung et al. established a B-cell line (SB) from an HCV-infected B-NHL, whose virions could infect primary human hepatocytes, PBMCs, and an established Bcell line (Raji cells) in vitro [83]. Further studies provided evidence that HCV replicates in various hematopoietic cell types, including peripheral dendritic cells, monocytes, and macrophages [84-86]. Overall, despite the evidence that $\mathrm{HCV}$ can infect B-cells, the results about its capacity to replicate in B-cells and other blood mononuclear cells and to induce direct malignant lymphoproliferation still appear highly conflicting $[16,29]$.

A Japanese group recently established HCV transgenic mice that expressed the full $\mathrm{HCV}$ genome in $\mathrm{B}$ cells (RzCD19Cre mice) [87]. Interestingly, RzCD19Cre mice with substantially elevated serum-soluble interleukin2 receptor $\alpha$-subunit (sIL-2R $\alpha$ ) levels developed B-NHL. Another mouse model of lymphoproliferative disorder was established by persistent expression of $\mathrm{HCV}$ structural proteins through disruption of interferon regulatory factor-1 (irf-1 $1^{-/-} / \mathrm{CN} 2$ mice). Irf-1 ${ }^{-/-} / \mathrm{CN} 2$ mice showed extremely high incidences of lymphomas and lymphoproliferative disorders. Moreover, these mice showed increased levels of interleukin (IL)-2 and IL-10, as well as increased Bcl2 expression, which promoted oncogenic transformation of lymphocytes. In this mouse model, the overexpression of apoptosis-related proteins and/or aberrant cytokine production were the primary events involved in inducing lymphoproliferation [87].

A recent study found that peripheral blood B-cells from patients with chronic HCV infection were infected and also had enhanced gene expression associated with BNHL development when compared to healthy controls [88]. Furthermore, HCV has been found to induce high mutation frequency of cellular genes (immunoglobulin heavy chain, Bcl-6, p53 and beta-catenin genes), in B-cell lines and PBMCs in vitro, by inducing double strand breaks and by activating error-prone-polymerases and AID [89]. These mutations of cellular genes are amplified in $\mathrm{HCV}$-associated B-NHL in vivo, suggesting that HCV-induced mutations in proto-oncogenes and tumor suppressor genes may lead to oncogenetic transformation of the infected B-cells. The so-called mutator phenotype induced by HCV acute and chronic infection in B-cells may be considered a "hit and run" mechanism of cell transformation (Figure 1(D)) [89].

It has been proposed that HCV uses B-cells as reservoirs for persistent infection, which could result in the enhanced 
expression of lymphomagenesis-related genes, particularly AID, which is thought to be crucial for the initiation and progression of B-NHL [67]. Other studies suggested that the evolution from lymphoproliferation to malignancy may require a second transforming event such as the antiapoptotic Bcl-2 rearrangement. The $t(14 ; 18)$ translocation is indeed significantly associated with chronic HCV infection and particularly with MC $[90,91]$. Although the role of virus penetration and replication in B-cells has still to be fully clarified, several evidences suggest that the presence of HCV virus or HCV proteins in these cells represents an oncogenic stimulus $[16,29]$.

\section{Conclusion}

Epidemiological studies have clearly demonstrated a correlation between chronic $\mathrm{HCV}$ infection and occurrence of B-NHL. The clinical evidence that antiviral therapy has a significant role in the treatment and prevention of some HCV-associated lymphoproliferative disorders, especially indolent B-NHL, further supports the existence of an etiopathogenetic link. The mechanisms exploited by HCV to induce B-cell lymphoproliferation differ from the classical mechanisms of herpesviral-induced lymphomagenesis, which require the maintenance of either EBV or human herpesvirus- 8 genomes in the transformed B-cells as clonal episomes, together with the expression of an array of latent and, to a lesser extent, of lytic proteins [92]. It is conceivable that the different mechanisms proposed, namely, chronic antigen stimulation, high-affinity interaction between HCVE2 protein, and its cellular receptors, direct HCV infection of B-cells and "hit and run" transforming events, are not mutually exclusive, but they may be combined themselves in a multifactorial model of $\mathrm{HCV}$-associated lymphomagenesis (Figure 1(A-D)) [16, 26, 29, 67].

\section{Conflict of Interests}

The authors indicated that there are no potential conflicts of interests.

\section{Acknowledgments}

This work was supported by Associazione Italiana per la Ricerca sul Cancro, Milan, Italy GRANT No. (AIRC IG10621-2010).

\section{References}

[1] B. Clarke, "Molecular virology of hepatitis C virus," Journal of General Virology, vol. 78, no. 10, pp. 2397-2410, 1997.

[2] A. O. De Beeck, L. Cocquerel, and J. Dubuisson, "Biogenesis of Hepatitis C virus envelope glycoproteins," Journal of General Virology, vol. 82, no. 11, pp. 2589-2595, 2001.

[3] P. Pileri, Y. Uematsu, S. Campagnoli et al., "Binding of hepatitis C virus to CD81," Science, vol. 282, no. 5390, pp. 938941, 1998.
[4] B. D. Lindenbach, M. J. Evans, A. J. Syder et al., "Virology: complete replication of hepatitis C virus in cell culture," Science, vol. 309, no. 5734, pp. 623-626, 2005.

[5] S. Levy, S. C. Todd, and H. T. Maecker, "CD81 (TAPA-1): a molecule involved in signal transduction and cell adhesion in the immune system," Annual Review of Immunology, vol. 16, pp. 89-109, 1998.

[6] M. G. Ghany, D. B. Strader, D. L. Thomas, and L. B. Seeff, "Diagnosis, management, and treatment of hepatitis C: an update," Hepatology, vol. 49, no. 4, pp. 1335-1374, 2009.

[7] H. R. Rosen, "Chronic hepatitis C infection," New England Journal of Medicine, vol. 364, no. 25, pp. 2429-2438, 2011.

[8] J. Amin, G. J. Dore, D. L. O’Connell et al., "Cancer incidence in people with hepatitis $\mathrm{B}$ or $\mathrm{C}$ infection: a large communitybased linkage study," Journal of Hepatology, vol. 45, no. 2, pp. 197-203, 2006.

[9] R. Strauss, A. Törner, A. S. Duberg, R. Hultcrantz, and K. Ekdahl, "Hepatocellular carcinoma and other primary liver cancers in hepatitis C patients in Sweden-a low endemic country," Journal of Viral Hepatitis, vol. 15, no. 7, pp. 531-537, 2008.

[10] G. Pozzato, C. Mazzaro, M. Crovatto et al., "Low-grade malignant lymphoma, hepatitis $\mathrm{C}$ virus infection, and mixed cryoglobulinemia," Blood, vol. 84, no. 9, pp. 3047-3053, 1994.

[11] V. Agnello, R. T. Chung, and L. M. Kaplan, "A role for hepatitis C virus infection in Type II cryoglobulinemia," New England Journal of Medicine, vol. 327, no. 21, pp. 1490-1495, 1992.

[12] C. Ferri, A. L. Zignego, and S. A. Pileri, "Cryoglobulins," Journal of Clinical Pathology, vol. 55, no. 1, pp. 4-13, 2002.

[13] C. Ferri, F. Caracciolo, A. L. Zignego et al., "Hepatitis C virus infection in patients with non-Hodgkin's lymphoma," British Journal of Haematology, vol. 88, no. 2, pp. 392-394, 1994.

[14] A. Mele, A. Pulsoni, E. Bianco et al., "Hepatitis C virus and B-cell non-Hodgkin lymphomas: an Italian multicenter casecontrol study," Blood, vol. 102, no. 3, pp. 996-999, 2003.

[15] M. Luppi, G. Longo, M. G. Ferrari et al., "Clinico-pathological characterization of hepatitis C virus-related B- cell nonHodgkin's lymphomas without symptomatic cryoglobulinemia," Annals of Oncology, vol. 9, no. 5, pp. 495-498, 1998.

[16] F. Marcucci and A. Mele, "Hepatitis viruses and non-Hodgkin lymphoma: epidemiology, mechanisms of tumorigenesis, and therapeutic opportunities," Blood, vol. 117, no. 6, pp. 17921798, 2011.

[17] A. S. Evans and N. E. Mueller, "Viruses and cancer. Causal associations," Annals of Epidemiology, vol. 1, no. 1, pp. 71-92, 1990.

[18] P. Cocco, G. Piras, M. Monne et al., "Risk of malignant lymphoma following viral hepatitis infection," International Journal of Hematology, vol. 87, no. 5, pp. 474-483, 2008.

[19] A. M. Pellicelli, M. Marignani, and V. Zoli, "Hepatitis C virusrelated subtypes in non Hodgkin's lymphoma," World Journal of Hepatology, vol. 3, pp. 278-284, 2011.

[20] F. Mizorogi, J. Hiramoto, A. Nozato et al., "Hepatitis C virus infection in patients with B-cell non-Hodgkin's lymphoma," Internal Medicine, vol. 39, no. 2, pp. 112-117, 2000.

[21] L. Goldman, S. Ezzat, N. Mokhtar et al., "Viral and nonviral risk factors for non-Hodgkin's lymphoma in Egypt: heterogeneity by histological and immunological subtypes," Cancer Causes and Control, vol. 20, no. 6, pp. 981-987, 2009.

[22] P. Hausfater, P. Cacoub, Y. Sterkers et al., "Hepatitis C virus infection and lymphoproliferative diseases: prospective study on 1,576 patients in France," American Journal of Hematology, vol. 67, no. 3, pp. 168-171, 2001. 
[23] J. D. Collier, B. Zanke, M. Moore et al., "No association between hepatitis C and B-cell lymphoma," Hepatology, vol. 29, no. 4, pp. 1259-1261, 1999.

[24] T. Sy and M. M. Jamal, "Epidemiology of hepatitis C virus (HCV) infection," International Journal of Medical Sciences, vol. 3, no. 2, pp. 41-46, 2006.

[25] J. P. Gisbert, L. García-Buey, M. J. Pajares, and R. MorenoOtero, "Prevalence of hepatitis $\mathrm{C}$ virus infection in B-cell nonHodgkin's lymphoma: systematic, review and meta-analysis," Gastroenterology, vol. 125, no. 6, pp. 1723-1732, 2003.

[26] M. Luppi, P. Barozzi, L. Potenza, G. Riva, M. Morselli, and G. Torelli, "Is it now the time to update treatment protocols for lymphomas with new anti-virus systems?" Leukemia, vol. 18, no. 10, pp. 1572-1575, 2004.

[27] L. Dal Maso and S. Franceschi, "Hepatitis C virus and risk of lymphoma and other lymphoid neoplasms: a meta-analysis of epidemiologic studies," Cancer Epidemiology Biomarkers and Prevention, vol. 15, no. 11, pp. 2078-2085, 2006.

[28] K. Matsuo, A. Kusano, A. Sugumar, S. Nakamura, K. Tajima, and N. E. Mueller, "Effect of hepatitis C virus infection on the risk of non-Hodgkin's lymphoma: a meta-analysis of epidemiological studies," Cancer Science, vol. 95, no. 9, pp. 745-752, 2004.

[29] S. K. Hartridge-Lambert, E. M. Stein, A. J. Markowitz, and C. S. Portlock, "Hepatitis C and non-Hodgkin lymphoma: the clinical perspective," Hepatology, vol. 55, pp. 634-641, 2012.

[30] L. A. Martyak, M. Yeganeh, and S. Saab, "Hepatitis C and lymphoproliferative disorders: from mixed cryoglobulinemia to non-Hodgkin's lymphoma," Clinical Gastroenterology and Hepatology, vol. 7, no. 8, pp. 900-905, 2009.

[31] C. Besson, D. Cantoni, E. Lepage et al., "Characteristics and outcome of diffuse large B-cell lymphoma in hepatitis $\mathrm{C}$ viruspositive patients in LNH 93 and LNH 98 groupe d'etude des lymphomes de l'adulte programs," Journal of Clinical Oncology, vol. 24, no. 6, pp. 953-960, 2006.

[32] D. Ennishi, Y. Maeda, N. Niitsu et al., "Hepatic toxicity and prognosis in hepatitis $\mathrm{C}$ virus-infected patients with diffuse large B-cell lymphoma treated with rituximab-containing chemotherapy regimens: a Japanese multicenter analysis," Blood, vol. 116, no. 24, pp. 5119-5125, 2010.

[33] M. Luppi, M. G. Ferrari, and G. Torelli, "Hepatitis C virus genotype distribution in B-cell non-Hodgkin lymphoma," Annals of Internal Medicine, vol. 128, no. 7, p. 602, 1998.

[34] H. A. Torres, M. Nevah-Rubin, B. J. Barnett et al., "Variation of hepatitis $\mathrm{C}$ virus genotype distribution between geographically related patients: a retrospective multicenter," Journal of Clinical Oncology, vol. 29, supplement, ASCO Meeting Abstract no. 8052, 2011.

[35] O. Hermine, F. Lefrère, J. P. Bronowicki et al., "Regression of splenic lymphoma with villous lymphocytes after treatment of hepatitis C virus infection," New England Journal of Medicine, vol. 347, no. 2, pp. 89-94, 2002.

[36] D. Vallisa, P. Bernuzzi, L. Arcaini et al., "Role of anti-hepatitis $\mathrm{C}$ virus (HCV) treatment in HCV-related, low-grade, B-cell, non-Hodgkin's lymphoma: a multicenter Italian experience," Journal of Clinical Oncology, vol. 23, no. 3, pp. 468-473, 2005.

[37] L. Arcaini, D. Vallisa, M. Merli et al., "Hematological response to antiviral therapy in 94 patients with indolent B-cell lymphomas associated with hepatitis $\mathrm{C}$ virus infection: a study of the Fondazione Italiana Linfomi (FIL)," Annals of Oncology, vol. 22, Lugano Meeting Abstract no. 138, pp. 128-129, 2011.

[38] J. P. Gisbert, L. García-Buey, J. M. Pajares, and R. MorenoOtero, "Systematic review: regression of lymphoproliferative disorders after treatment for hepatitis C infection," Alimentary Pharmacology and Therapeutics, vol. 21, no. 6, pp. 653-662, 2005.

[39] V. La Mura, A. D. Renzo, F. Perna et al., "Antiviral therapy after complete response to chemotherapy could be efficacious in HCV-positive non-Hodgkin's lymphoma," Journal of Hepatology, vol. 49, no. 4, pp. 557-563, 2008.

[40] Y. Kawamura, K. Ikeda, Y. Arase et al., "Viral Elimination Reduces Incidence of Malignant Lymphoma in Patients with Hepatitis C," American Journal of Medicine, vol. 120, no. 12, pp. 1034-1041, 2007.

[41] F. Poordad, J. McCone, B. R. Bacon et al., "Boceprevir for untreated chronic HCV genotype 1 infection," New England Journal of Medicine, vol. 364, no. 13, pp. 1195-1206, 2011.

[42] I. M. Jacobson, J. G. McHutchison, G. Dusheiko et al., "Telaprevir for previously untreated chronic hepatitis $\mathrm{C}$ virus infection," New England Journal of Medicine, vol. 364, no. 25, pp. 2405-2416, 2011.

[43] J. Pawlotsky, "The results of phase III clinical trials with telaprevir and boceprevir presented at the liver meeting 2010: a new standard of care for hepatitis C virus genotype 1 infection, but with issues still pending," Gastroenterology, vol. 140, no. 3, pp. 746-754, 2011.

[44] A. Nooka, P. J. Shenoy, R. Sinha et al., "Hepatitis C reactivation in patients who have diffuse large B-cell lymphoma treated with rituximab: a case report and review of literature," Clinical Lymphoma Myeloma and Leukemia, vol. 11, pp. 379-384, 2011.

[45] M. Merli, M. Spina, S. Luminari et al., "Prognostic models to predict survival in indolent and aggressive non-Hodgkin's lymphomas associated with hepatitis C virus infection: a multicenter Italian study on 1, 043 patients," in Proceedings of the 52nd American Society of Hematology Annual Meeting, vol. 116, no. 2821, 2010.

[46] S. Vento, F. Cainelli, F. Mirandola et al., "Fulminant hepatitis on withdrawal of chemotherapy in carriers of hepatitis C virus," Lancet, vol. 347, no. 8994, pp. 92-93, 1996.

[47] M. C. Cox, M. A. Aloe-Spiriti, and E. Cavalieri, "HCV infection, B-cell non-Hodgkin's lymphoma and immunochemotherapy: evidence and open questions," World Journal of Gastrointestinal Oncology, vol. 15, pp. 46-53, 2012.

[48] D. A. Landau, D. Saadoun, L. H. Calabrese, and P. Cacoub, "The pathophysiology of HCV induced B-cell clonal disorders," Autoimmunity Reviews, vol. 6, no. 8, pp. 581-587, 2007.

[49] A. Stathis, F. Bertoni, and E. Zucca, "Treatment of gastric marginal zone lymphoma of MALT type," Expert Opinion on Pharmacotherapy, vol. 11, no. 13, pp. 2141-2152, 2010.

[50] A. Zullo, C. Hassan, A. Andriani et al., "Treatment of lowgrade gastric MALT-lymphoma unresponsive to Helicobacter pylori therapy: a pooled-data analysis," Medical Oncology, vol. 27, no. 2, pp. 291-295, 2010.

[51] V. De Re, S. De Vita, A. Marzotto et al., "Pre-malignant and malignant lymphoproliferations in an HCV-infected type II mixed cryoglobulinemic patient are sequential phases of an antigen-driven pathological process," International Journal of Cancer, vol. 87, pp. 211-216, 2000.

[52] P. D. Gorevic and B. Frangione, "Mixed cryoglobulinemia cross-reactive idiotypes: implications for the relationship of MC to rheumatic and lymphoproliferative diseases," Seminars in Hematology, vol. 28, no. 2, pp. 79-94, 1991.

[53] R. Marasca, P. Vaccari, M. Luppi et al., "Immunoglobulin gene mutations and frequent use of VH1-69 and VH4-34 segments in hepatitis $\mathrm{C}$ virus-positive and hepatitis $\mathrm{C}$ virus-negative 
nodal marginal zone B-cell lymphoma," American Journal of Pathology, vol. 159, no. 1, pp. 253-261, 2001.

[54] T. Allander, K. Drakenberg, A. Beyene et al., "Recombinant human monoclonal antibodies against different conformational epitopes of the E2 envelope glycoprotein of hepatitis $\mathrm{C}$ virus that inhibit its interaction with CD81," Journal of General Virology, vol. 81, no. 10, pp. 2451-2459, 2000.

[55] C. H. Chan, K. G. Hadlock, S. K. H. Foung, and S. Levy, "VH169 gene is preferentially used by hepatitis $C$ virus-associated $B$ cell lymphomas and by normal B cells responding to the E2 viral antigen," Blood, vol. 97, no. 4, pp. 1023-1026, 2001.

[56] V. De Re, S. De Vita, A. Marzotto et al., "Sequence analysis of the immunoglobulin antigen receptor of hepatitis $C$ virus Associated non-Hodgkin lymphomas suggests that the malignant cells are derived from the rheumatoid factorn Producing cells that occur mainly in type II cryoglobulinemia," Blood, vol. 96, no. 10, pp. 3578-3584, 2000.

[57] R. Lesniewski, G. Okasinski, R. Carrick et al., "Antibody to hepatitis $\mathrm{C}$ virus second envelope (HCV-E2) glycoprotein: a new marker of HCV infection closely associated with viremia," Journal of Medical Virology, vol. 45, no. 4, pp. 415-422, 1995.

[58] E. R. Quinn, C. H. Chan, K. G. Hadlock, S. K. H. Foung, M. Flint, and S. Levy, "The B-cell receptor of a hepatitis $\mathrm{C}$ virus (HCV)-associated non-Hodgkin lymphoma binds the viral E2 envelope protein, implicating HCV in lymphomagenesis," Blood, vol. 98, no. 13, pp. 3745-3749, 2001.

[59] S. Hermouet, I. Corre, M. Gassin, E. Bigot-Corbel, C. A. Sutton, and J. W. Casey, "Hepatitis C virus, human herpesvirus 8, and the development of plasma-cell leukemia," New England Journal of Medicine, vol. 348, no. 2, pp. 178-179, 2003.

[60] A. K. Matsumoto, D. R. Martin, R. H. Carter, L. B. Klickstein, J. M. Ahearn, and D. T. Fearon, "Functional dissection of the CD21/CD19/TAPA-1/Leu-13 complex of B lymphocytes," Journal of Experimental Medicine, vol. 178, no. 4, pp. 14071417, 1993.

[61] R. H. Carter and D. T. Fearon, "CD19: lowering the threshold for antigen receptor stimulation of B lymphocytes," Science, vol. 256, no. 5053, pp. 105-107, 1992.

[62] D. Rosa, G. Saletti, E. De Gregorio et al., "Activation of naïve B lymphocytes via CD81, a pathogenetic mechanism for hepatitis C virus-associated B lymphocyte disorders," Proceedings of the National Academy of Sciences of the United States of America, vol. 102, no. 51, pp. 18544-18549, 2005.

[63] A. Wack, E. Soldaini, C. Tseng -TK, S. Nuti, G. R. Klimpel, and S. Abrignani, "Binding of the hepatitis $C$ virus envelope protein E2 to CD81 provides a costimulatory signal for human T cells," European Journal of Immunology, vol. 31, pp. 166-175, 2001.

[64] M. Poetsch, K. Weber-Matthiesen, H. J. Plendl, W. Grote, and B. Schlegelberger, "Detection of the $t(14: 18)$ chromosomal translocation by interphase cytogenetics with Yeast-artificialchromosome probes in follicular lymphoma and nonneoplastic lymphoproliferation," Journal of Clinical Oncology, vol. 14, no. 3, pp. 963-969, 1996.

[65] Z. Chen, Y. Zhu, Y. Ren et al., "Hepatitis C virus protects human B lymphocytes from fas-mediated apoptosis via E2CD81 engagement," PLoS One, vol. 6, no. 4, Article ID e18933, 2011.

[66] K. Machida, K. T. H. Cheng, N. Pavio, V. M. H. Sung, and M. M. C. Lai, "Hepatitis C virus E2-CD81 interaction induces hypermutation of the immunoglobulin gene in $\mathrm{B}$ cells," Journal of Virology, vol. 79, no. 13, pp. 8079-8089, 2005.
[67] M. Ito, H. Kusunoki, and K. Mochida, "HCV infection and B-cell lymphomagenesis," Advances in Hematology, vol. 2011, Article ID 835314, 8 pages, 2011.

[68] M. Houghton, A. Weiner, J. Han, G. Kuo, and Q. L. Choo, "Molecular biology of the hepatitis $\mathrm{C}$ viruses: implications for diagnosis, development and control of viral disease," Hepatology, vol. 14, no. 2, pp. 381-388, 1991.

[69] J. H. Han, V. Shyamala, K. H. Richman et al., "Characterization of the terminal regions of hepatitis C viral RNA: identification of conserved sequences in the 5' untranslated region and poly(A) tails at the 3' end," Proceedings of the National Academy of Sciences of the United States of America, vol. 88, no. 5, pp. 1711-1715, 1991.

[70] A. L. Zignego, D. Macchia, M. Monti et al., "Infection of peripheral mononuclear blood cells by hepatitis C virus," Journal of Hepatology, vol. 15, no. 3, pp. 382-386, 1992.

[71] C. Ferri, M. Monti, L. La Civita et al., "Infection of peripheral blood mononuclear cells by hepatitis $\mathrm{C}$ virus in mixed cryoglobulinemia," Blood, vol. 82, no. 12, pp. 3701-3704, 1993.

[72] M. Inokuchi, T. Ito, M. Uchikoshi et al., "Infection of B cells with hepatitis $\mathrm{C}$ virus for the development of lymphoproliferative disorders in patients with chronic hepatitis C," Journal of Medical Virology, vol. 81, no. 4, pp. 619-627, 2009.

[73] G. Morsica, G. Tambussi, G. Sitia et al., "Replication of hepatitis C virus in B lymphocytes (CD19+)," Blood, vol. 94, no. 3, pp. 1138-1139, 1999.

[74] D. Sansonno, A. R. Iacobelli, V. Cornacchiulo, G. Iodice, and F. Dammacco, "Detection of hepatitis C virus (HCV) proteins by immunofluorescence and HCV RNA genomic sequences by non-isotopic in situ hybridization in bone marrow and peripheral blood mononuclear cells of chronically HCVinfected patients," Clinical and Experimental Immunology, vol. 103, no. 3, pp. 414-421, 1996.

[75] R. E. Lanford, D. Chavez, F. V. Chisari, and C. Sureau, "Lack of detection of negative-strand hepatitis $C$ virus RNA in peripheral blood mononuclear cells and other extrahepatic tissues by the highly strand- specific rTth reverse transcriptase PCR," Journal of Virology, vol. 69, no. 12, pp. 8079-8083, 1995.

[76] M. Willems, H. Moshage, and Sing Hiem Yap, "PCR and detection of negative HCV RNA strands," Hepatology, vol. 17, no. 3, p. 526, 1993.

[77] S. Marukian, C. T. Jones, L. Andrus et al., "Cell cultureproduced hepatitis $\mathrm{C}$ virus does not infect peripheral blood mononuclear cells," Hepatology, vol. 48, no. 6, pp. 1843-1850, 2008.

[78] Z. Stamataki, C. Shannon-Lowe, J. Shaw et al., "Hepatitis $\mathrm{C}$ virus association with peripheral blood B lymphocytes potentiates viral infection of liver-derived hepatoma cells," Blood, vol. 113, no. 3, pp. 585-593, 2009.

[79] M. P. Curry, L. Golden-Mason, D. G. Doherty et al., "Expansion of innate CD5pos B cells expressing high levels of CD81 in hepatitis C virus infected liver," Journal of Hepatology, vol. 38, no. 5, pp. 642-650, 2003.

[80] Y. Sugawara, M. Makuuchi, N. Kato, K. Shimotohno, and K. Takada, "Enhancement of hepatitis $\mathrm{C}$ virus replication by Epstein-Barr virus-encoded nuclear antigen 1," EMBO Journal, vol. 18, no. 20, pp. 5755-5760, 1999.

[81] A. M. Levine, S. Shimodaira, and M. M. C. Lai, "Treatment of HCV-related mantle-cell lymphoma with ribavirin and pegylated interferon alfa," New England Journal of Medicine, vol. 349, no. 21, pp. 2078-2079, 2003. 
[82] M. Ohsawa, Y. Tomita, M. Hashimoto, H. Kanno, and K. Aozasa, "Hepatitis C viral genome in a subset of primary hepatic lymphomas," Modern Pathology, vol. 11, no. 5, pp. 471-478, 1998.

[83] M. H. V. Sung, S. Shimodaira, A. L. Doughty et al., "Establishment of B-cell lymphoma cell lines persistently infected with hepatitis $\mathrm{C}$ virus in vivo and in vitro: the apoptotic effects of virus infection," Journal of Virology, vol. 77, no. 3, pp. 21342146, 2003.

[84] C. Caussin-Schwemling, C. Schmitt, and F. Stoll-Keller, "Study of the infection of human blood derived monocyte/macrophages with hepatitis C virus in vitro," Journal of Medical Virology, vol. 65, pp. 14-22, 2001.

[85] J. Greeve, A. Philipsen, K. Krause et al., "Expression of activation-induced cytidine deaminase in human B-cell nonHodgkin lymphomas," Blood, vol. 101, no. 9, pp. 3574-3580, 2003.

[86] M. C. Navas, A. Fuchs, E. Schvoerer, A. Bohbot, A. M. Aubertin, and F. Stoll-Keller, "Dendritic cell susceptibility to hepatitis C virus genotype 1 infection," Journal of Medical Virology, vol. 67, no. 2, pp. 152-161, 2002.

[87] K. Tsukiyama-Kohara, S. Sekiguchi, Y. Kasama, N. E. Salem, K. Machida, and M. Kohara, "Hepatitis C virus-related lymphomagenesis in a mouse model," ISRN Hematology, vol. 2011, Article ID 167501, 8 pages, 2011.

[88] M. Ito, K. Murakami, T. Suzuki et al., "Enhanced expression of lymphomagenesis-related genes in peripheral blood B cells of chronic hepatitis C patients," Clinical Immunology, vol. 135, no. 3, pp. 459-465, 2010.

[89] K. Machida, K. T. N. Cheng, V. M. H. Sung et al., "Hepatitis $\mathrm{C}$ virus induces a mutator phenotype: enhanced mutations of immunoglobulin and protooncogenes," Proceedings of the National Academy of Sciences of the United States of America, vol. 101, no. 12, pp. 4262-4267, 2004.

[90] Y. Kitay-Cohen, A. Amiel, N. Hilzenrat et al., "Bcl-2 rearrangement in patients with chronic hepatitis $\mathrm{C}$ associated with essential mixed cryoglobulinemia type II," Blood, vol. 96, no. 8, pp. 2910-2912, 2000.

[91] A. L. Zignego, C. Ferri, F. Giannelli et al., "Prevalence of bcl-2 rearrangement in patients with hepatitis $C$ virus-related mixed cryoglobulinemia with or without B-cell lymphomas," Annals of Internal Medicine, vol. 137, no. 7, pp. 571-580, 2002.

[92] S. Swaminathan, "Molecular biology of Epstein-Barr virus and Kaposi's sarcoma-associated herpesvirus," Seminars in Hematology, vol. 40, no. 2, pp. 107-115, 2003. 


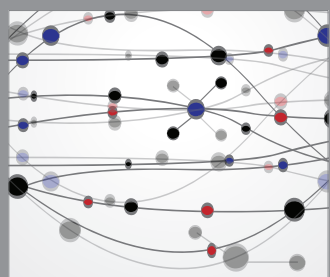

The Scientific World Journal
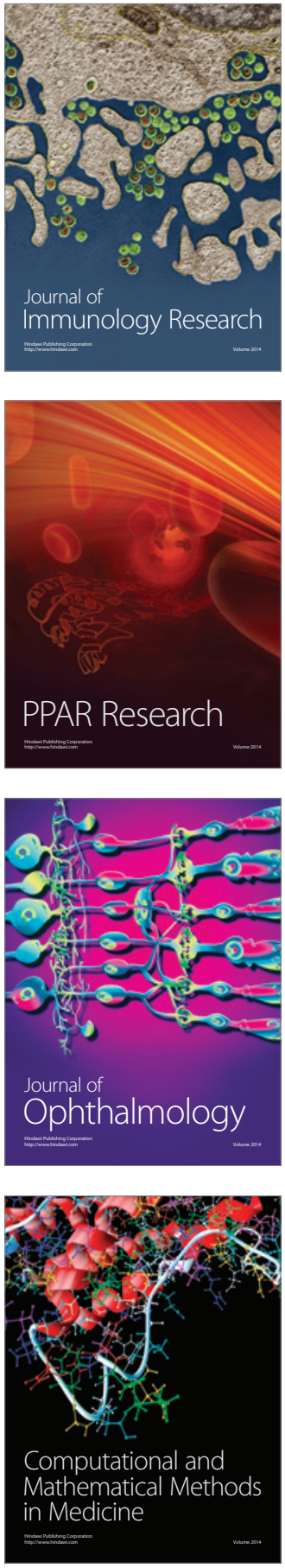

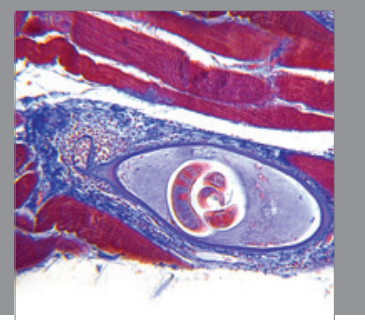

Gastroenterology

Research and Practice
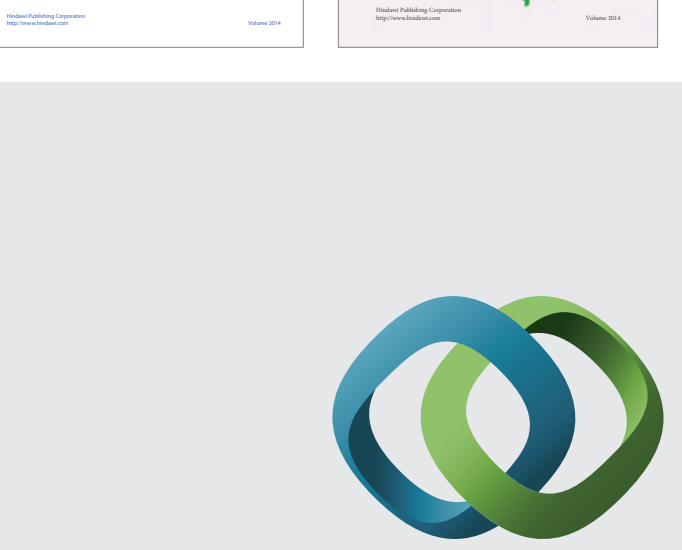

\section{Hindawi}

Submit your manuscripts at

http://www.hindawi.com
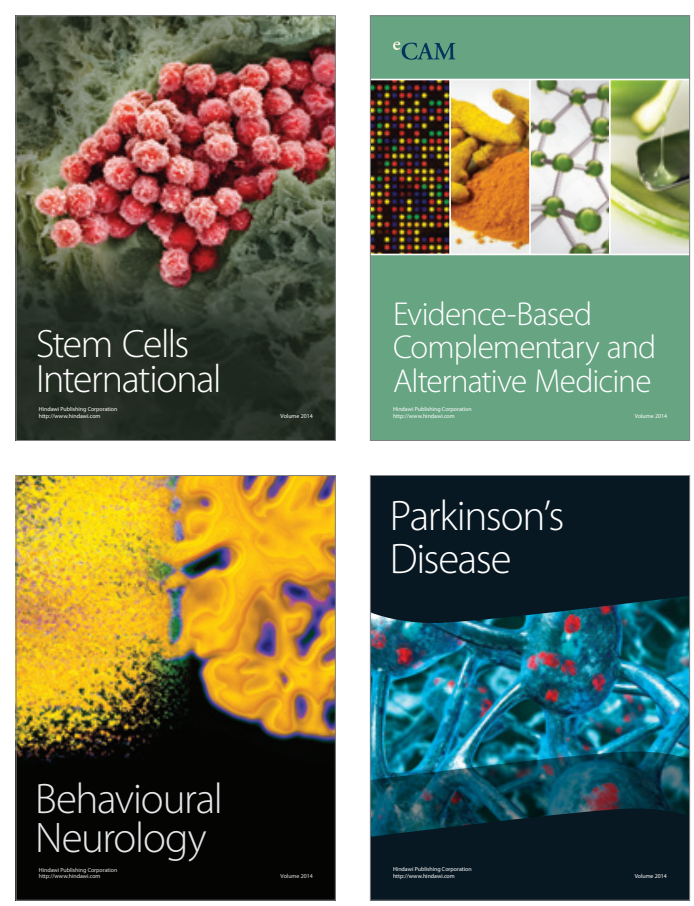

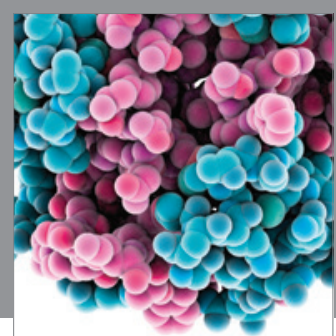

Journal of
Diabetes Research

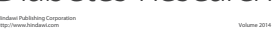

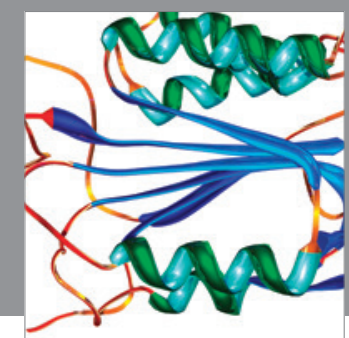

Disease Markers
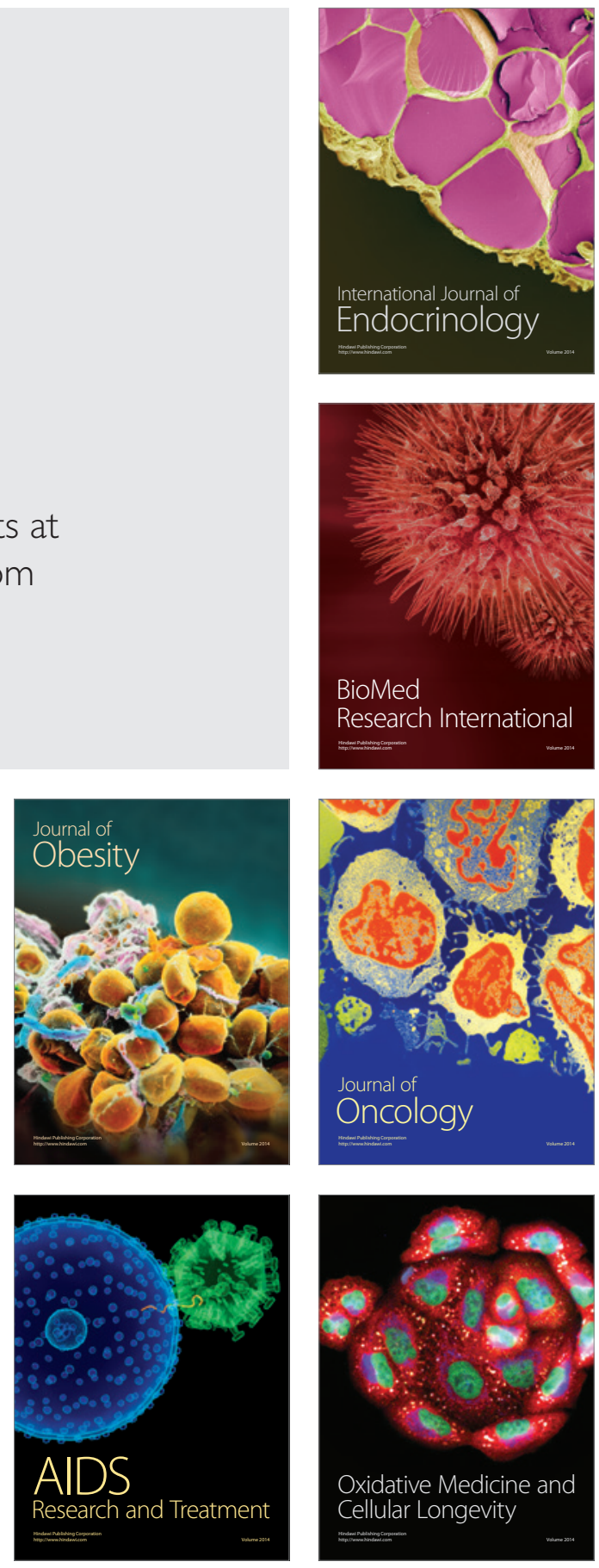